\title{
Cystone in cystine stone formers
}

\author{
Pralhad Sadashiv Patki
}

Received: 29 October 2010/Accepted: 10 February 2011/Published online: 27 February 2011

(C) Springer-Verlag 2011

This is in response to a trial conducted by Dr. Erickson at Mayo Clinic in a paper titled "Cystone for one year did not change urine chemistry or decrease stone burden in cystine stone formers" [1]. This paper describes the results of clinical evaluation of Cystone in 10 patients. One of the important shortcomings of the study is inclusion of patients with cystine stones of long-standing duration, and probably had undergone every possible treatment. The authors mention that these were refractory patients particularly difficult to treat. When these patients did not respond to medical treatment for sufficient duration, it may not be appropriate to include them in this type of study. It is almost impossible to dislodge an impacted stone with medication and invariably requires surgical intervention.

Despite a small number of patients included in this study, the biochemical data is available only for 12 out of 20 observations indicating that the data collection is insufficient for statistical evaluation. A careful analysis of this limited data does indicate that there is a trend in diuresis and reduction in urinary excretion of cystine, though it does not meet the statistical significance.

This study was initiated because the authors met a patient with cystine stone who had experienced a near miraculous cure. Probably the author was curious to investigate whether Cystone is a "Miracle Cure". Miracle cure rarely exists in science, but makes no mistake, once a miracle is published in a peer-reviewed medical journal; the damage has already been done [2]. Cystone has never been claimed as a miracle cure. It is claimed to be effective in the management of nephrolithiasis wherein the stone size is $<1.5 \mathrm{~cm} \mathrm{[3,4].}$

The question is not about the efficacy of Cystone, but the way the clinical trial was designed and executed leading to ambiguous and conflicting results. A well-designed study should include a larger population size which follow Gaussian distribution baseline so as to increase the statistical strength in discriminating the efficacy or otherwise.

\section{References}

1. Erickson SB, Vrtiska TJ, Canzanello VJ, Lieske JC (2010) Cystone for one year did not change urine chemistry or decrease stone burden in cystine stone formers. Urol Res (in press)

2. Flamm BL (2004) Faith healing confronts modern medicine. Sci Rev Alter Med 8(1):9-14

3. Mohanty NK, Nayak RL, Patki PS (2010) Safety and efficacy of Ayurvedic formulation Cystone in the management of ureteric calculi-a prospective randomized placebo controlled study. Am J Pharmacol Toxic 5(2):58-64

4. Karmakar D, Patki PS (2010) Evaluation of efficacy and safety of herbal formulation Cystone in the management of Urolithiasismeta analysis of 50 clinical studies. Internet J Alter Med 8:1-18
P. S. Patki $(\square)$

The Himalaya Drug Company, Makali, Bangalore 562 123, India

e-mail: dr.patki@himalayahealthcare.com 